\title{
O autoconceito de adolescentes escolares ${ }^{1}$
}

\author{
Ana Alayde Werba Saldanha ${ }^{2}$ \\ Isabel Cristina Vasconcelos de Oliveira \\ Regina Ligia Wanderlei de Azevedo \\ Universidade Federal da Paraíba, João Pessoa-PB, Brasil
}

\begin{abstract}
Resumo: Este estudo objetivou identificar e comparar o autoconceito dos adolescentes escolares de uma amostra da cidade de João Pessoa-PB, Brasil, associado às variáveis sexo, faixa etária e tipo de escola frequentada (pública ou privada). Para tanto foi utilizado o Inventário dos Esquemas de Gênero do Autoconceito em 686 adolescentes estudantes. De modo geral, os adolescentes apresentaram autoconceito positivo, variando em função do sexo (maior para o feminino), idade (quanto menor a idade, maior a percepção negativa masculina e a feminina com maior evidência entre os 16 e 18 anos) e tipo de escola (autoconceito mais positivo na escola pública). Estes resultados fornecem subsídios para a elaboração de estratégias mais coerentes com o perfil dos adolescentes, seja no âmbito familiar, escolar ou social.
\end{abstract}

Palavras-chave: autoconceito, adolescentes, estudantes.

\section{The self-concept of school adolescents}

\begin{abstract}
This study objectives identify and compare the self-concept of school adolescents of a sample of the city of , João Pessoa - PB, Brazil, the variables involving sex, age and type of school attended (public or private). For this was implemented the Inventory of Schemes Genre of Self-Concept in 686 adolescent students. In general, young people have positive self-concept, depending on the sex (higher for females), age (the lower the age, the greater the negative perception male and female most obviously with between 16 and 18 years) and type of school (more positive self-concept in public school). These results provide subsidies for the development of strategies more consistent with the profile of adolescents, whether in the family, school or social.
\end{abstract}

Keywords: self-concept, adolescents, students.

\section{El autoconcepto de adolescentes escolares}

Resumen: Este estudio objetivó identificar y comparar el autoconcepto de los adolescentes escolares de una muestra de la ciudad João Pessoa - PB, Brasil, asociado a las variables sexo, franja de edad y tipo de escuela frecuentada (pública o privada). Para tanto fue utilizado el Inventario de los Esquemas de Género del Autoconcepto en 686 adolescentes estudiantes. De modo general, los adolescentes presentaron autoconcepto positivo, variando en función del sexo (mayor para el femenino), edad (cuánto menor la edad, mayor la percepción negativa masculina y femenina con mayor evidencia entre los 16 y 18 años) y tipo de escuela (autoconcepto más positivo en la escuela pública). Estos resultados producen subsidios para la elaboración de estrategias más coherentes con el perfil de los adolescentes, sea en el contexto familiar, escolar o social.

Palabras clave: autoconcepto, adolescentes, estudiantes.

O conceito que os indivíduos elaboram deles próprios procede dos processos cognitivos e é caracterizado como um sistema complexo e dinâmico de percepções, crenças e atitudes de um indivíduo sobre si mesmo, que atua na interpretação e organização das experiências dos sujeitos, estando passível a influência de fatores internos e externos (D’Affonseca, 2005). A teoria do autoconceito propõe que este construto é formado por um conjunto de esquemas cognitivos denominados autoesquemas que correspondem às construções que resumem as nossas experiências passadas e que permitem aos indivíduos compreenderem as suas próprias experiências sociais e organizar a ampla variedade de informações que possuem sobre

\footnotetext{
${ }^{1}$ Este texto foi revisado seguindo Acordo Ortográfico da Língua Portuguesa (1990), em vigor a partir de $1^{\circ}$ de janeiro de 2009.

${ }^{2}$ Endereço para correspondência:

Regina Ligia Wanderlei de Azevedo. R. Rosa Lima dos Santos, 132, Apt $^{\circ}$ 201. Bancários CEP 58.051-590. João Pessoa-PB, Brasil. E-mail: regina. azevedo@gmail.com
}

si mesmos (Giavoni \& Tamayo, 2000). Dessa forma, pode-se definir o autoconceito como uma estrutura cognitiva que organiza as experiências passadas do indivíduo (reais ou imaginárias), controla o processo informativo relacionado consigo mesmo e exerce uma função de autorregulação (Tamayo e cols., 2001).

O autoconceito pode ser descrito, ainda, como as representações mentais das características pessoais utilizadas pelo indivíduo para a definição de si mesmo e regulação do seu comportamento, sendo denominadas de esquemas cognitivos ou os já referidos autoesquemas. Os esquemas, afirmam Tamayo e cols. (2001), moldam as percepções que os indivíduos possuem das situações, suas memórias dos eventos e seus sentimentos sobre si mesmos e sobre os outros. Os múltiplos autoesquemas de um indivíduo, no entanto, não podem ser processados simultaneamente; portanto, num determinado momento, somente um número limitado deles será processado. Como tais autores propõem, esse conjunto de autoesquemas acessíveis apenas em tal momento, recebe o nome de autoconceito de trabalho, que pode 
ser influenciado tanto por processos introspectivos, como pelo contexto externo no qual um indivíduo está inserido.

Essas percepções construídas e as atitudes a elas correspondentes (autoconceito), segundo Burns (1979), possuem três componentes básicos: (a) o avaliativo/afetivo, (b) o cognitivo e (c) o comportamental. O primeiro destes é definido por Coopersmith (1967) como autoestima e corresponde à avaliação global que o indivíduo possui acerca do seu próprio valor. A autoestima, de acordo com Gobitta e Guzzo (2002) e Myers (2000), é um construto muito complexo e corresponde ao quanto o indivíduo está satisfeito com a sua autoimagem relacionando-a, sempre, com o social. Com base nesta proposta, Losel e Bliesener (1994, citados por Ito, Gobitta, \& Guzzo, 2007) apontam a resiliência como importante aspecto para a manutenção deste componente que acaba sendo refletido em um autoconceito mais positivo e ativo. O componente cognitivo é constituído pelas percepções que o indivíduo tem dos traços, das características e das habilidades que possui ou que pretende possuir. O último componente, o comportamental, consiste nas estratégias de autoapresentação utilizadas pelo indivíduo, com o objetivo de transmitir aos outros uma imagem positiva de si mesmo. Embora estes três componentes sejam totalmente diferentes, eles estão relacionados entre si, com o intuito de produzir o autoconceito percebido por cada sujeito.

O interesse pelo estudo do autoconceito desenvolveu-se no contexto da fenomenologia existencial e deu origem, rapidamente, a numerosas pesquisas e publicações. $\mathrm{O}$ primeiro estudioso a analisar sistematicamente a noção de autoconceito foi William James (1980), cuja contribuição configura-se como extremamente importante por constituir uma ruptura com a abordagem fisiológica da época e por introduzir a dimensão social no autoconceito. James (1890, citado por Costa, 2002), considerou a consciência do indivíduo sobre o que se está pensando ou a consciência do que se está percebendo em relação aos aspectos e processos físicos, bem como as idéias que as pessoas têm sobre como elas são e o que elas gostariam de ser. Este fenômeno, segundo Costa (2002), é caracterizado na Psicologia como pensamentos autorreferentes, também denominados como autoimagem, identidade e autoconceito.

Alguns anos mais tarde, Baldwin apresentou o autoconceito numa perspectiva social e cultural, sendo reiterada por Cooley e Mead (citado por Tamayo e cols., 2001). No entanto, o desenvolvimento do behaviorismo provocou um enfraquecimento na produção de pesquisas sobre o tema, tendo em vista que a concepção behaviorista não considera construtos tão "mentalistas". Posteriormente, Allport, juntamente com a crescente influência das abordagens experimental e cognitivista, incitaram o desenvolvimento de pesquisas científicas acerca do autoconceito, que vem configurando-se atualmente como um diversificado campo de estudos.

A partir destes pressupostos, pode-se inferir que o autoconceito não é um construto imutável. Sua elaboração sofre constantemente alterações oriundas da cultura, do feedback dado pela sociedade e de outras variáveis de natureza diversa, especialmente aquelas de ordem relacional e social (Melo, Giavoni, \& Tróccoli, 2004; Tamayo e cols., 2001). Em consequência, observa-se uma incoerência nas suas implicações, decorrentes de situações vivenciadas pelos indivíduos, da subjetividade social e da ação do tempo.

O autoconceito, então, é concebido como uma construção teórica que o indivíduo realiza sobre si a partir de sua interação com o meio social. Esta autoconstrução é um reflexo das percepções, conjecturas e imaginações que o indivíduo realiza a respeito da influência que a sua imagem exerce sobre os outros, do julgamento que estes (outros significativos) realizam sobre o indivíduo, somados a uma espécie de autosentimento (orgulho ou vergonha) resultante desta interação social (Giavoni \& Tamayo, 2003). Segundo Costa (2002), diversos autores abordam o autoconceito através do seu aspecto multidimensional, da organização hierárquica de suas dimensões e da influência da interação social na origem, estruturação e desenvolvimento do mesmo, lidando com seus vários componentes bem como suas interrelações; e mesmo aqueles autores que o enfocam como unitário estão simplesmente aprofundando um de seus aspectos.

Um dos modelos de autoconceito, proposto por Shavelson, Hubner e Stanton (1976, citado por D’Affonseca, 2005), considera o autoconceito como um construto organizado e estruturado, multifacetado e hierárquico, que se apresenta mais estável nos aspectos mais gerais (autoconceito geral), em detrimento dos níveis hierárquicos mais baixos (autoconceito físico, social ou emocional). Ratificando esta perspectiva, destaca-se o trabalho de Sisto e Martinelli (2004), ao investigarem o autoconceito em crianças e jovens, discriminando-o em social (como o indivíduo se percebe em relações sociais), escolar (relações relativas ao contexto escolar), familiar (comportamento adotado no lar) e pessoal (modo de agir).

Outro modelo consiste na síntese de numerosas noções abordadas por diferentes modelos de autoconceito elaboradas a partir de 1890, detalhando-o em cinco dimensões: (a) selfmaterial, compreendendo o corpo e suas particularidades, às quais os indivíduos se identificam de uma maneira ou de outra; (b) self-pessoal, correspondentes às características interiorizadas ou íntimas, formuladas pelo indivíduo; (c) self-adaptativo, o qual corresponde às reações que o indivíduo tem em face das percepções de si mesmo, negativas ou positivas; (d) self-social, que indica se a pessoa é confiante em si mesma e interage com os outros; por fim, (e) self e não-self, que agrega significados de situações onde a pessoa não fala diretamente dela mesma, mas somente dos outros e de situações onde o indivíduo está envolvido pelo julgamento dos outros à sua pessoa (L'Écuyer, 1978, citado por Costa, 2002).

A importância do estudo do autoconceito na adolescência está relacionada com a sua capacidade preditiva dos mais variados comportamentos em diferentes contextos de vida, entre eles o escolar, já que se pressupõe que os estudantes "que possuem elevada auto-estima são mais capazes de implementar com sucesso outros aspectos de seus autoconceitos" 
(Lassance, 2005, p. 43-44). Assim, adolescentes que subestimam as suas capacidades têm expectativas negativas acerca da sua realização futura, evitam a ação, pensam que os outros esperam menos deles e percebem os seus esforços e os seus investimentos como menos regulares e eficazes, sobreavaliando o grau de exigência das tarefas de realização e sentindo de forma mais negativa a pressão e as exigências dos vários contextos, bem como as pressões dos outros significativos (pais, professores, treinadores e, particularmente, dos pares). A desvalorização de si próprio conduz a um subaproveitamento das potencialidades individuais e, frequentemente, a menores expectativas por parte dos outros em relação ao indivíduo, o que conduz à atribuição de objetivos menos desafiantes (Faria, 2005).

Nesta perspectiva, a escola tem ocupado um papel de importância na vida afetiva da criança e do adolescente, ao mesmo tempo em que fornece elementos para eles se autoconhecerem. De acordo com Da Cunha, Sisto e Machado (2006), o autoconceito escolar trata de questões relativas às relações interpessoais que ocorrem no contexto escolar. Os critérios se referem à avaliação de suas possibilidades de liderança, de ser academicamente visto como esperto e de seus colegas aceitarem suas colocações, ao mesmo tempo em que é reconhecido como uma pessoa bondosa e divertida, tanto no sentido positivo como no negativo.

Outro aspecto deste construto está relacionado ao relacionamento familiar, cuja qualidade interfere na sua formação. Cia e Barham (2005) concluíram, a partir de suas investigações, que a frequência mais elevada com que os pais se inter-relacionam com seus filhos interfere positivamente na autopercepção destes últimos, sobretudo nos itens referentes aos assuntos escolares. Peixoto (2004) corrobora tais achados, mas limita a extensão dessa influência. Ele propõe que a qualidade das relações familiares introduz diferenças nas dimensões acadêmicas, mas não na autoestima dos sujeitos, em virtude desta última sofrer alterações preponderantemente na adolescência.

A relação entre gênero e autoconceito, segundo Bernardo e Matos (2003), na maioria dos casos é consistente no que diz respeito quer às diferenças, quer às similaridades entre sexos. As diferenças de gênero consistentes com os estereótipos sexuais parecem ocorrer em facetas específicas cujo padrão principal revela que o sexo feminino reporta consistentemente mais percepções desfavoráveis da sua aparência e da sua competência.

Partindo destes pressupostos e considerando apenas o componente cognitivo (Burns, 1979), este estudo teve como objetivo identificar o autoconceito de adolescentes escolares associando-o às variáveis sexo, tipo de escola frequentada (pública e particular) e faixa etária. Para tanto, utilizou-se a escala Inventário dos Esquemas de Gêneros do Autoconceito (IEGA) já validada por Giavoni e Tamayo (2000). No entanto, como a amostra da validação original não eram adolescentes, achou-se pertinente verificar, previamente as análises por gênero, tipo de escola e faixa etária, evidências de validade da IEGA no público adolescente, mas principalmente identificar a estrutura fatorial que emergiu para o público adolescente.

\section{Método}

\section{Participantes}

Trata-se de um estudo transversal, realizado na cidade de João Pessoa-PB, com uma amostragem não-probabilística e acidental. Participaram 686 adolescentes estudantes do ensino fundamental $(16 \%)$ e médio $(84 \%)$ de escolas públicas $(60 \%)$ e particulares $(40 \%)$ da capital paraibana, sendo a maioria do sexo feminino (54\%), com média de idade de 16 anos (desvio padrão $=2,04$; com intervalo de 12 a 21 anos), divididos nas seguintes faixas etárias: $12-15=250 ; 16-18=364 ; 19-21=72$.

\section{Instrumentos}

Foi utilizado o Inventário dos Esquemas de Gênero do Autoconceito (IEGA), construído e validado por Giavoni e Tamayo (2000) para uma população de universitários, composto por 83 itens. As respostas são dadas em uma escala do tipo Likert variando de: (0) não me identifico; (1) identifico-me levemente; (2) identifico-me moderadamente; (3) identifico-me demasiadamente e (4) identifico-me totalmente.

Foi aplicado também um questionário sócio-demográfico, com o objetivo de melhor caracterizar o perfil da amostra e de ter um maior controle sobre variáveis externas que possam interferir nos resultados da pesquisa, como idade, sexo, nível de escolaridade, tipo de escola e atividade remunerada.

\section{Considerações éticas}

A coleta de dados foi iniciada após aprovação do estudo pelo Comitê de Ética em Pesquisa do Centro de Ciências da Saúde da Universidade Federal da Paraíba, protocolo no 249 , e assinatura do Termo de Consentimento Livre e Esclarecido, tanto pelos diretores das escolas participantes quanto pelos adolescentes.

\section{Procedimentos}

\section{Coleta de dados}

Os dados foram coletados em sala de aula durante o período escolar regular, seguindo os seguintes passos: (a) apresentação dos aplicadores e exposição dos objetivos da pesquisa; (b) reiteração sobre o anonimato dos participantes e a confidencialidade de suas respostas; (c) informação sobre a livre deliberação de cada um em responder; e, por fim, (d) instruções específicas sobre a forma de responder aos questionários. O tempo de aplicação teve duração aproximada de 30 minutos.

\section{Análise dos dados}

Em análise preliminar realizada sobre os dados obtidos na amostra total de adolescentes, foram identificados os casos 
faltosos (missing values) que foram inferiores a 5\% e substituídos pelas médias obtidas para cada variável. Para avaliar os casos de outliers multivariados, optou-se por analisar, separadamente, as escalas masculina e feminina que compõem o instrumento, visto que os casos de outliers multivariados que possam existir frente aos itens de uma das escalas, podem não ser os mesmos casos frente aos itens da outra escala. Na escala masculina foram encontrados apenas outliers moderados que, após análise e verificação de que não interferiam nas variáveis, optou-se por mantê-los. Na escala feminina foram encontrados 13 casos de outliers multivariados severos. Estes casos foram retirados da amostra, restando um total de 686 sujeitos, sendo 322 do sexo masculino e 364 do sexo feminino.

Com a finalidade de se averiguar a fatorabilidade da matriz de correlações entre os itens desta medida, procedeu-se à comprovação do índice Kaiser-Meyer-Olkin (KMO) e ao teste de esfericidade de Bartlett. O primeiro trabalha com as correlações parciais das variáveis, devendo ser aceitos índices iguais ou superiores a 0,6 (Tabachinick \& Fidell, 1996). O segundo, por outro lado, comprova a hipótese de que a matriz de covariâncias é uma matriz de identidade. O poder discriminativo dos itens foi estabelecido por grupos critérios internos, ou seja, considerando os $50 \%$ dos escores totais abaixo e acima do ponto de corte, aqui considerado o número 3 da escala de respostas. Mediante o uso do teste $t$, foram comparadas as médias para cada item com o objetivo de verificar o poder de discriminação entre os grupos. As extrações fatoriais foram realizadas por meio do método dos Componentes Principais, considerando-se os itens com cargas fatoriais iguais ou superiores a 0,35 . Para avaliar os índices de consistência interna dos fatores utilizou-se o alfa de Cronbach. O gráfico scree plot foi utilizado como sinalizador na opção do número de fatores a serem extraídos.

\section{Resultados}

Concordando com Giavoni e Tamayo (2000) ao postularem que o autoconceito é uma estrutura que sofre a influência da cultura, e sendo os conceitos de masculinidade e feminilidade construções da subjetividade social, optou-se por analisar as escalas separadamente por sexo.

\section{Escala Masculina}

A Análise dos Componentes Principais apresentou os seguintes resultados para a escala masculina: (a) Kaiser-MeyerOlkin $(K M O=0,79$; (b) Bartlett's Test of Sphericity $(3403)=$ 9667,424; $p<0,001$; )c) número de componentes (eigenvalue $>2)=6$ e (d) variância total explicada pelos seis componentes: $36,12 \%$. De acordo com o gráfico scree plot foi definida a extração de quatro fatores que explicam conjuntamente $28,31 \%$ da variância total, conforme pode ser observado na Tabela 1.

Ressalta-se que 23 itens do instrumento original não obtiveram saturações aceitáveis, ou seja, não atenderam ao critério previamente definido $(0,35)$, por esta razão não figuram em nenhum dos fatores descritos. São eles: invejoso, despreocupado, inábil, frio, indeciso, descrente, cuidadoso, realista, objetivo, aventureiro, passivo, fiel, exatas, retraído, leal, discreto, dependente, submisso, competitivo, racional, delicado, compassivo e resignado.

Tabela 1

Estrutura fatorial do Inventário de Autoconceito masculino

\begin{tabular}{|c|c|c|c|c|}
\hline \multirow{2}{*}{ Variáveis } & \multicolumn{4}{|c|}{ Fatores } \\
\hline & 1 & 2 & 3 & 4 \\
\hline Desagradável & ,617 & & & \\
\hline Desatencioso &, 595 & & & \\
\hline Violento &, 580 & & & \\
\hline Intolerante &, 575 & & & \\
\hline Incompetente &, 568 & & & \\
\hline Grosseiro &, 561 & & & \\
\hline Irresponsável &, 558 & & & \\
\hline Desorganizado &, 519 & & & \\
\hline Desajustado &, 517 & & & \\
\hline Injusto &, 500 & & & \\
\hline Responsável &,- 499 & & & \\
\hline Mesquinho & ,486 & & & \\
\hline Desleixado &, 480 & & & \\
\hline Agressivo & ,479 & & & \\
\hline Desobediente & ,478 & & & \\
\hline Imoral &, 477 & & & \\
\hline Respeitoso &,- 473 & & & \\
\hline Irritado &, 447 & & & \\
\hline Desesperançado & ,445 & & & \\
\hline Malicioso &, 444 & & & \\
\hline Simpático &,- 437 & & & \\
\hline Incompreensivo & ,414 & & & \\
\hline Oprimido & ,401 & & & \\
\hline Antipático & ,398 & & & \\
\hline Inacessível & ,394 & & & \\
\hline Compreensivo &,- 387 & & & \\
\hline Insensato & ,382 & & & \\
\hline Vulgar & 367 & & & \\
\hline Imprudente & 355 & & & \\
\hline Frágil & &, 514 & & \\
\hline Dominador & & ,502 & & \\
\hline Elegante & & ,480 & & \\
\hline Sentimental & & ,466 & & \\
\hline Ajustado & & ,464 & & \\
\hline Dócil & & 455 & & \\
\hline Romântico & & 455 & & \\
\hline Caprichoso & & ,445 & & \\
\hline Amoroso & & ,437 & & \\
\hline Íntegro & & ,432 & & \\
\hline
\end{tabular}

(continua...) 
Tabela 1

(continuação)

\begin{tabular}{|c|c|c|c|c|}
\hline \multirow{2}{*}{ Variáveis } & \multicolumn{4}{|c|}{ Fatores } \\
\hline & 1 & 2 & 3 & 4 \\
\hline Dedicado & & ,421 & & \\
\hline Rígido & & ,418 & & \\
\hline Sonhador & & ,418 & & \\
\hline Intransigente & & ,412 & & \\
\hline Emotivo & & ,410 & & \\
\hline Sensual & & ,410 & & \\
\hline Sensível & & ,408 & & \\
\hline Irreverente & & ,408 & & \\
\hline Vaidoso & & ,404 & & \\
\hline Atraente & & ,401 & & \\
\hline Harmônico & & ,400 & & \\
\hline Razão & & ,395 & & \\
\hline Conciliador & & ,389 & & \\
\hline Moral & &, 364 & & \\
\hline Dominado & & ,359 & & \\
\hline Ousado & & &,- 434 & \\
\hline Hedonista & & &,- 411 & \\
\hline Tímido & & &, 383 & \\
\hline Inseguro & & & ,368 & \\
\hline Organizado & & & &,- 464 \\
\hline Tolerante & & & & ,421 \\
\hline Numero de Itens & 29 & 25 & 4 & 2 \\
\hline Valor Próprio & 9,57 & 8,12 & 3,32 & 2,48 \\
\hline \% Variância Total & 11,53 & 9,79 & 4,00 & 2,99 \\
\hline Alfa de Cronbach & 0,85 & 0,86 & 0,26 & 0,11 \\
\hline
\end{tabular}

Os termos utilizados para designar cada fator seguiram um dos seguintes critérios: (a) denominar o fator com o item que apresenta a maior carga fatorial ou (b) denominar o fator segundo a sua característica geral. Observa-se, assim, a seguinte conformação dos fatores:

Fator 1 - Percepção Negativa de Si: é composto por 31 itens, cujas saturações variaram de 0,62 (desagradável) a 0,35 (imprudente), com valor próprio (eingenvalue) de 9,57, explicando $11,53 \%$ da variância total, com consistência interna (Alpha de Cronbach) de 0,85. Caracteriza-se por adjetivos negativos associados a uma concepção particular de si, que podem incitar no adolescente o desenvolvimento de condutas para adequar ao autoconceito, ou seja, o indivíduo que se considera "mau" modela seus atos para se enquadrar nessa concepção, desempenhando, consequentemente, um papel que lhe é atribuído (Souza, 2002), papéis estes rotulados como "os transgressores".

Fator 2 - Percepção Positiva de Si: é composto por 25 itens, com saturações variando de 0,51 (frágil) a 0,36 (dominado), com valor próprio (eingenvalue) de 8,12 , explicando $9,79 \%$ da variância total, com consistência interna (Alpha de Cronbach) de 0,86 . Caracteriza-se por adjetivos positivos associados à autoestima elevada e capacidade de empatia.

Fator 3 - Passividade: composto por quatro itens, com saturações variando de $-0,43$ (ousado) a 0,37 (inseguro), com valor próprio (eingenvalue) de 3,32, explicando $4 \%$ da variância total, com consistência interna (Alpha de Cronbach) de 0,26. Caracteriza-se por adjetivos fortes associados a cognições negativas, que podem levar a um fraco senso de auto-eficácia, baixa auto-estima, sentimentos de impotência e dificuldade de tomar decisões.

Fator 4 - Tolerância: composto por dois itens, com saturações variando de 0,51 (retraído) a 0,35 (submisso), com valor próprio (eingenvalue) de 2,48, explicando 3\% da variância total, com consistência interna (Alpha de Cronbach) de 0,11. Caracterizase por adjetivos associados à tolerância e desorganização.

Observa-se, portanto, que a escala masculina de autoconceito de adolescentes é constituída por dois fatores fortes - Percepção Negativa de Si e Sensibilidade - e dois fatores complementares, Passividade e Organização.

\section{Escala Feminina}

A Análise dos Componentes Principais apresentou os seguintes resultados para a escala feminina: (a) Kaiser-MeyerOlkin $(K M O)=0,77$; (b) Bartlett's Test of Sphericity (3403) = 9478,156; $p<0,001$; (c) número de componentes (eigenvalue $>2$ ) $=6$ e (d) variância total explicada pelos seis componentes: $31,25 \%$.

De acordo com o gráfico scree plot foi definida a extração de quatro fatores que explicam conjuntamente $21,8 \%$ da variância total, conforme pode ser observado na Tabela 2.

Tabela 2

Estrutura fatorial do Inventário de Autoconceito feminino

\begin{tabular}{lccc}
\hline \multirow{2}{*}{\multicolumn{1}{c}{ Variáveis }} & \multicolumn{3}{c}{ Fatores } \\
\cline { 2 - 3 } & $\mathbf{1}$ & $\mathbf{2}$ & $\mathbf{3}$ \\
\hline Desobediente &, 557 & & \\
Intransigente &, 539 & \\
Violento &, 538 & \\
Injusto &, 536 & \\
Desajustado &, 535 & \\
Agressivo &, 528 & \\
Insensato &, 525 & \\
Intolerante &, 511 & \\
Irritado &, 498 & \\
Desorganizado &, 493 & \\
Grosseiro &, 469 & \\
Malicioso &, 469 & \\
Incompreensivo &, 461 & \\
Desleixado &, 461 & \\
Irresponsável &, 450
\end{tabular}

(continua...) 
Tabela 2

(continuação)

\begin{tabular}{|c|c|c|c|}
\hline \multirow{2}{*}{ Variáveis } & \multicolumn{3}{|c|}{ Fatores } \\
\hline & 1 & 2 & 3 \\
\hline Imoral & ,448 & & \\
\hline Imprudente & ,430 & & \\
\hline Dominador &, 430 & & \\
\hline Inseguro & ,424 & & \\
\hline Desatencioso & ,419 & & \\
\hline Desagradável & ,415 & & \\
\hline Incompetente & ,396 & & \\
\hline Dominado & ,369 & & \\
\hline Desesperançado &, 364 & & \\
\hline Antipático & ,356 & & \\
\hline Oprimido &, 352 & & \\
\hline Amoroso & &, 570 & \\
\hline Dócil & &, 554 & \\
\hline Elegante & &, 545 & \\
\hline Caprichoso & &, 526 & \\
\hline Romântico & &, 514 & \\
\hline Harmônico & &, 510 & \\
\hline Respeitoso & & ,490 & \\
\hline Hedonista & & ,488 & \\
\hline Objetivo & & ,484 & \\
\hline Emotivo & & ,484 & \\
\hline Sentimental & & ,472 & \\
\hline Atraente & & ,459 & \\
\hline Frágil & &, 450 & \\
\hline Compreensivo & &, 450 & \\
\hline Simpático & & ,443 & \\
\hline Cuidadoso & & ,430 & \\
\hline Dedicado & &, 427 & \\
\hline Sensível & &, 424 & \\
\hline Razão & & ,420 & \\
\hline Vaidoso & & ,410 & \\
\hline Íntegro & & ,408 & \\
\hline Ajustado & & ,406 & \\
\hline Conciliador & &, 363 & \\
\hline Irreverente & & ,359 & \\
\hline Sensual & & &,- 508 \\
\hline Tímido & & &, 550 \\
\hline Retraído & & &, 515 \\
\hline Passivo & & & ,407 \\
\hline Ousado & & &,- 378 \\
\hline Tolerante & & & ,368 \\
\hline Numero de Itens & 26 & 24 & 06 \\
\hline Valor Próprio & 7,66 & 7,32 & 3,10 \\
\hline \% Variância Total & 9,23 & 8,83 & 3,74 \\
\hline Alfa de Cronbach & 0,86 & 0,85 & 0,19 \\
\hline
\end{tabular}

Do instrumento original 27 itens não obtiveram saturações aceitáveis, ou seja, não atenderam ao critério previamente definido $(0,35)$, por esta razão não figuram em nenhum dos fatores descritos. São eles: leal, discreto, submisso, descrente, vulgar, indeciso, competitivo, invejoso, racional, moral, inábil, aventureiro, rígido, mesquinho, sonhador, delicado, compassivo, frio, fiel, inacessível, despreocupado, resignado, dependente, realista, organizado, responsável, exatas.

A versão feminina da escala manteve os mesmos fatores da masculina, com a emersão de dois fatores fortes e um complementar, conforme pode ser observado abaixo:

Fator 1 - Percepção Negativa de Si: é composto por 26 itens, cujas saturações variaram de 0,56 (desobediente) a 0,35 (oprimido), com valor próprio (eingenvalue) de 7,66, explicando $9,23 \%$ da variância total, com consistência interna (Alpha de Cronbach) de 0,86.

Fator 2 - Percepção Positiva de Si: é composto por 24 itens, com saturações variando de 0,57 (amoroso) a 0,36 (irreverente), com valor próprio (eingenvalue) de 7,32 explicando 8,83\% da variância total, com consistência interna (Alpha de Cronbach) de 0,85 .

Fator 3 - Passividade: composto por 6 itens, com saturações variando de 0,58 (sensual) a 0,37 (tolerante), com valor próprio (eingenvalue) de 3,10, explicando 3,74\% da variância total, com consistência interna (Alpha de Cronbach) de 0,19.

\section{O autoconceito dos adolescentes}

O estudo entre as médias dos fatores apresenta diferenças em relação ao sexo dos participantes. Enquanto os adolescentes masculinos apresentaram maior índice médio nos fatores referente à Passividade, seguidos de Percepção Positiva de Si, Tolerância e Percepção Negativa de Si, as adolescentes femininas obtiveram pontuações médias mais elevadas nos fatores Percepção Positiva de Si, Passividade e Percepção Negativa de $\mathrm{Si}$, respectivamente, conforme pode ser observado na figura abaixo.

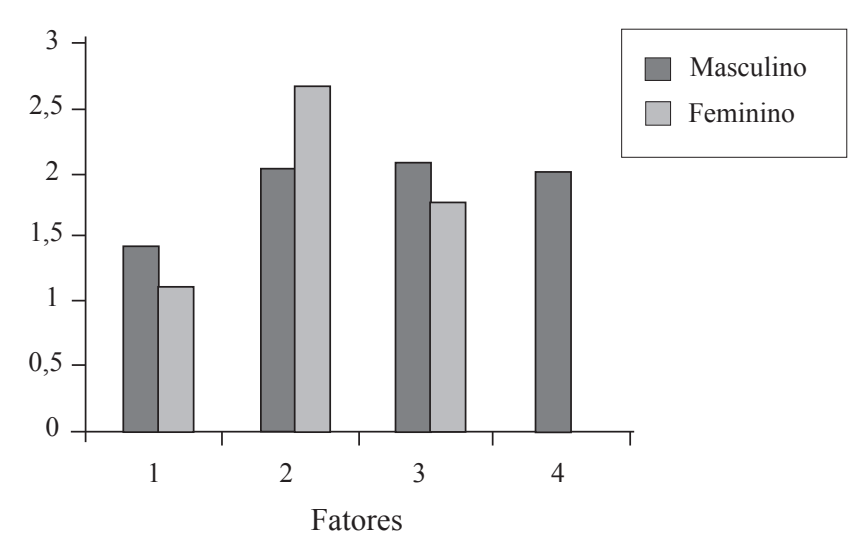

Figura 1. Comparação entre as médias dos fatores do IEGA masculino e feminino 
Foram realizadas comparações estatísticas entre os fatores do IEGA e as variáveis "tipo de escola" e "faixa etária". Para os fatores masculinos, em relação ao tipo de escola, foram encontradas diferenças estatisticamente significantes em relação ao fator 4 - organização $(t(306,385)=2,226-p=0,02)$, indicando que os estudantes masculinos das escolas públicas $(n=175)$ se identificam como mais organizados do que os das escolas privadas $(n=147)$. Em relação à faixa etária, foram encontradas diferenças significativas em relação ao fator 1 - Percepção Negativa de $\operatorname{Si}(\mathrm{F}(2)=2,958-\mathrm{p}=0,05)$ e ao fator $4-$ Tolerância $(F(2)=3,432-p=0,03)$, podendo-se inferir que quanto menor a idade, maior a Percepção Negativa de $\mathrm{Si}$, bem como quanto maior a idade, maior o autoconceito enquanto tolerante.
Para os fatores femininos foram encontradas diferenças estatisticamente significantes entre as médias do fator 2 - Percepção Positiva de $\mathrm{Si}(\mathrm{F}(2)=4,042-\mathrm{p}=0,01)$ e a faixa etária de 16 a 18 anos, indicando que estas adolescentes possuem maior auto-estima e autoconceito positivo. Não foi encontrada diferença estaticamente significante entre os fatores e o tipo de escola.

Buscando estabelecer um aprofundamento no perfil dos adolescentes, foram comparadas as médias dos adjetivos, considerando o sexo dos adolescentes e o tipo de escola frequentada (mediante o uso do teste $t$ ) e por faixa etária (ANOVA), conforme a Tabela 3 .

Tabela 3

Adjetivos com poder discriminativo em relação ao sexo, tipo de escola e faixa etária

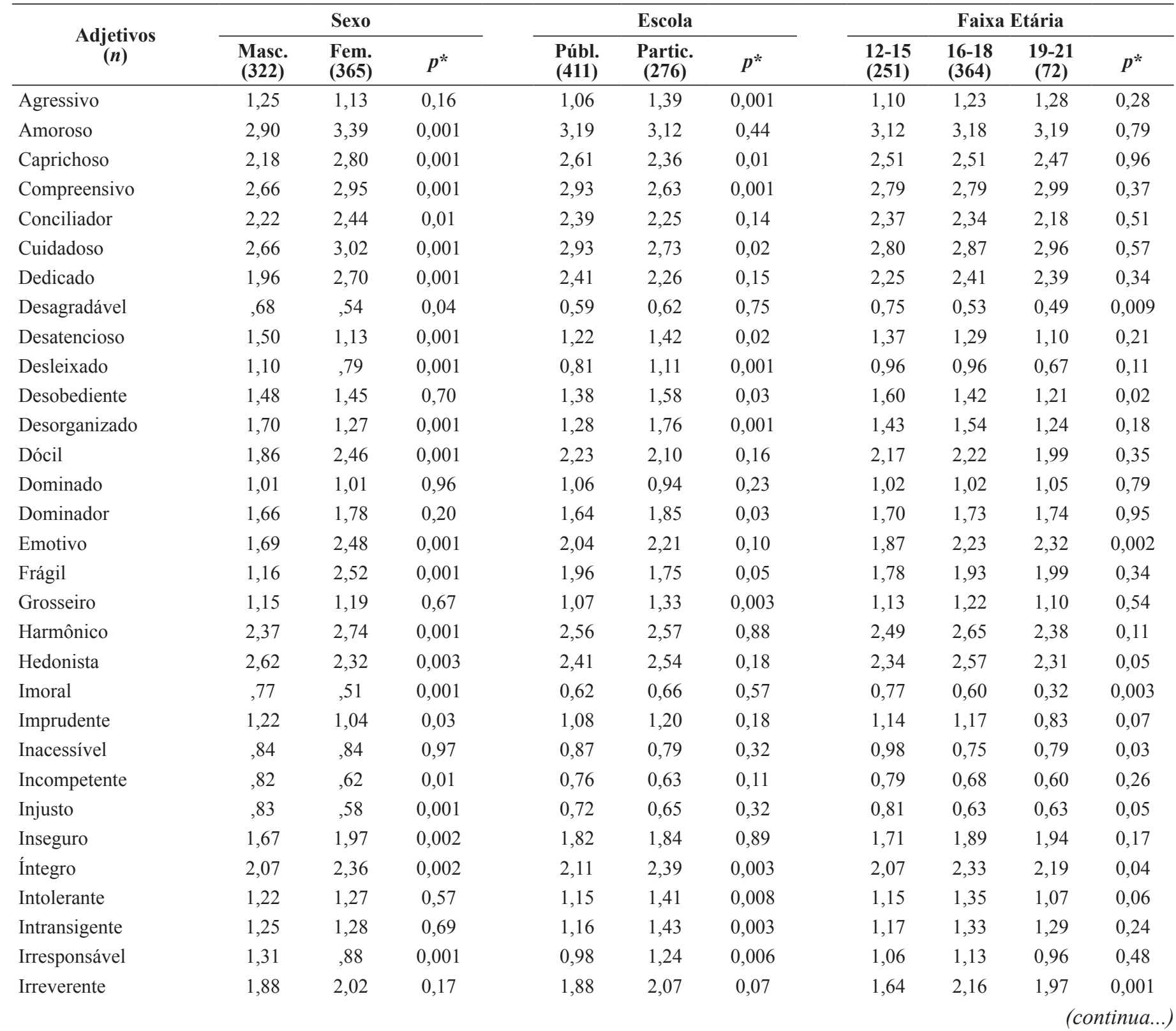


Tabela 3

(continuação)

\begin{tabular}{|c|c|c|c|c|c|c|c|c|c|c|}
\hline \multirow{2}{*}{$\begin{array}{c}\text { Adjetivos } \\
(n)\end{array}$} & \multicolumn{3}{|c|}{ Sexo } & \multicolumn{3}{|c|}{ Escola } & \multicolumn{4}{|c|}{ Faixa Etária } \\
\hline & $\begin{array}{c}\text { Masc. } \\
(\mathbf{3 2 2})\end{array}$ & $\begin{array}{l}\text { Fem. } \\
\text { (365) }\end{array}$ & $p^{*}$ & $\begin{array}{l}\text { Públ. } \\
\text { (411) }\end{array}$ & $\begin{array}{l}\text { Partic. } \\
\text { (276) }\end{array}$ & $p^{*}$ & $\begin{array}{l}12-15 \\
(251)\end{array}$ & $\begin{array}{l}16-18 \\
(364)\end{array}$ & $\begin{array}{c}19-21 \\
(72)\end{array}$ & $p^{*}$ \\
\hline Irritado & 1,61 & 1,78 & 0,68 & 1,61 & 1,83 & 0,02 & 1,60 & 1,79 & 1,61 & 0,17 \\
\hline Malicioso & 1,81 & 1,35 & 0,001 & 1,42 & 1,79 & 0,001 & 1,43 & 1,65 & 1,63 & 0,14 \\
\hline Mesquinho &, 74 & 62 & 0,13 & 0,65 & 0,71 & 0,45 & 0,81 & 0,60 & 0,58 & 0,03 \\
\hline Moral & 2,20 & 2,08 & 0,20 & 2,06 & 2,26 & 0,04 & 1,98 & 2,24 & 2,22 & 0,03 \\
\hline Oprimido & 1,33 & 1,09 & 0,01 & 1,25 & 1,13 & 0,21 & 1,22 & 1,18 & 1,28 & 0,81 \\
\hline Organizado & 2,09 & 2,67 & 0,001 & 2,63 & 2,06 & 0,001 & 2,44 & 2,32 & 2,67 & 0,82 \\
\hline Ousado & 2,03 & 1,82 & 0,03 & 1,79 & 2,11 & 0,001 & 1,78 & 2,05 & 1,71 & 0,01 \\
\hline Razão & 2,61 & 2,46 & 0,09 & 2,55 & 2,50 & 0,54 & 2,52 & 2,58 & 2,32 & 0,20 \\
\hline Respeitoso & 3,07 & 3,29 & 0,004 & 3,32 & 2,99 & 0,001 & 3,08 & 3,26 & 3,19 & 0,12 \\
\hline Sensível & 1,75 & 2,92 & 0,001 & 2,44 & 2,26 & 0,10 & 2,34 & 2,42 & 2,21 & 0,46 \\
\hline Sensual & 2,01 & 2,08 & 0,46 & 2,09 & 1,99 & 0,33 & 1,98 & 2,07 & 2,18 & 0,45 \\
\hline Sentimental & 2,20 & 3,15 & 0,001 & 2,80 & 2,56 & 0,02 & 2,73 & 2,70 & 2,64 & 0,86 \\
\hline Simpático & 2,93 & 3,23 & 0,001 & 3,15 & 3,00 & 0,05 & 3,14 & 3,07 & 3,03 & 0,68 \\
\hline Sonhador & 2,98 & 3,32 & 0,001 & 3,25 & 3,02 & 0,01 & 3,02 & 3,20 & 3,49 & 0,008 \\
\hline Vaidoso & 2,29 & 2,83 & 0,001 & 2,62 & 2,51 & 0,26 & 2,45 & 2,65 & 2,67 & 0,13 \\
\hline Violento & 97 &, 56 & 0,001 & 0,62 & 0,95 & 0,001 & 0,70 & 0,77 & 0,85 & 0,54 \\
\hline Vulgar &, 78 &, 31 & 0,001 & 0,54 & 0,52 & 0,76 & 0,67 & 0,49 & 0,25 & 0,001 \\
\hline
\end{tabular}

$* p<0,05$

Observa-se a existência de diferenças estatísticas em relação ao sexo para 37 adjetivos. Os adolescentes masculinos consideram-se mais desatenciosos, desleixados, desorganizados, imorais, injustos, irresponsáveis, maliciosos, violentos, vulgares, incompetentes, desagradáveis, rígidos, imprudentes, hedonistas, ousados e oprimidos. Para as adolescentes femininas houve maior identificação enquanto amorosas, caprichosas, compreensivas, cuidadosas, dedicadas, dóceis, emotivas, frágeis, harmônicas, organizadas, responsáveis, românticas, sensíveis, sentimentais, simpáticas, sonhadoras, vaidosas, inseguras, íntegras, respeitosas e conciliadoras. Estes conjuntos de adjetivos estão fortemente associados ao estereótipo social de gênero no qual persiste, ainda que veladamente, um sistema de normas e valores em relação aos papéis masculino e feminino, na divisão dos espaços de ação, domésticos e públicos, no qual faz parte da identidade feminina traços como a timidez, a fragilidade, o romantismo e a passividade, enquanto para o homem são valorizados aspectos como a agressividade e ousadia (Saldanha, 2003).

Entretanto, considerando os dez adjetivos com maiores médias (acima de 2,5) para cada um dos gêneros, observa-se que as adolescentes femininas se descrevem enquanto responsáveis, sensíveis, compreensivas, cuidadosas, sentimentais, românticas, simpáticas, respeitosas, sonhadoras e amorosas (média acima de 2,8), confirmando assim, os estereótipos de gênero associados à figura feminina. No entanto, os adolescentes masculinos se descrevem mais enquanto responsáveis, sonhadores, simpáticos, amorosos, objetivos, cuidadosos, compreensivos, hedonistas, que agem com a razão e românticos (média acima de 2,5), não emergindo nenhum adjetivo negativo e denotando-se aspectos de sensibilidade antes descritos como inerentes à figura feminina.

Em relação à diferença entre as redes de ensino pública e privada, emergiram 29 adjetivos com diferença estatisticamente significativa indicando que os alunos das escolas públicas apresentaram uma visão mais positiva de si próprios, definindo-se como mais caprichosos, compreensivos, cuidadosos, frágeis, organizados, responsáveis, românticos, sentimentais e sonhadores. Para os estudantes de escolas privadas ressaltaramse adjetivos mais negativos, tais como agressivos, desatenciosos, desleixados, desobedientes, desorganizados, dominadores, grosseiros, intolerantes, intransigentes, irresponsáveis, irreverentes, irritados, maliciosos, violentos, mas também íntegros, morais, respeitosos, objetivos e ousados.

Analisando de acordo com a faixa etária, observa-se a emergência de 16 adjetivos com poder discriminativo. Tais 
resultados apontam que, quanto menor a idade, maior o número de adjetivos negativos (desagradável, desobediente, imoral, inacessível, injusto, mesquinho e vulgar). Ao contrário, quanto maior a idade, surgem adjetivos como moral, responsável, objetivo, ao mesmo tempo em que emergem enquanto emotivos e sonhadores. A faixa etária intermediária, dos 16 aos 18 anos, ressalta adjetivos ligados ao espírito aventureiro, como hedonista, ousado e irreverente, mas também íntegro.

\section{Discussão}

Partindo-se do pressuposto de que o autoconceito tem um papel mediacional em todo o processo de identidade, influenciando em todos os aspectos da vida das pessoas, tendo a fase da adolescência como preponderante neste processo, o presente estudo objetivou identificar e comparar o autoconceito dos adolescentes escolares de uma amostra da cidade de João Pessoa$\mathrm{PB}$, associado às variáveis sexo, faixa etária e tipo de escola freqüentada (pública ou privada).

Analisando de forma geral, os resultados demonstram que estes adolescentes apresentaram autoconceito positivo, não tendo sido computado fatores negativos acima do ponto mediano da escala. Entretanto, visto que o autoconceito é uma estrutura fortemente influenciada pela cultura e devido às diferenças educacionais impostas pelos meios sócio-culturais para homens e mulheres, espera-se que os esquemas masculino e feminino difiram em função do sexo. Há poucos estudos em literatura que descrevem diferenças no autoconceito de homens e mulheres (Giavoni \& Tamayo, 2003), razão pela qual os resultados foram analisados diferenciados por sexo.

Um estudo realizado por Assis e cols. (2003), acerca da representação social que os adolescentes fazem de si próprio, ou seja, seu autoconceito, demonstrou, assim como no presente estudo, uma visão positiva e otimista de si, contudo não enfatiza a diferenciação de representação tendo como base a variável sexo.

No presente estudo, os fatores extraídos pela escala masculina trazem como mais forte a Passividade, estando associado a cognições negativas, que podem levar a um fraco senso de auto-eficácia, baixa auto-estima, sentimentos de impotência e dificuldade de tomar decisões, evocando uma postura passiva frente aos eventos cotidianos, de forma a tornarem-se pouco responsivos a estes. Esta característica pode trazer implicações no âmbito escolar, trazendo prejuízo para o adolescente, ou no familiar, interferindo no afeto do mesmo pelo não/pouco engajamento neste tipo de atividade (Lassance, 2005). Este fator é seguido pelos fatores Percepção Positiva de Si e Tolerância. A Percepção Negativa de Si emerge notadamente como o mais fraco dos fatores. Pode-se inferir, portanto, que os adolescentes masculinos, apesar de possuíram autoconceito positivo, sentem-se impotentes, passivos e tolerantes diante dos acontecimentos.

Os resultados observados a partir da escala feminina demonstram que as adolescentes femininas têm alta Percepção
Positiva de $\mathrm{Si}$, associada à auto-estima elevada e a capacidade de empatia. Apesar de apresentar como segundo fator a passividade, é com índice bem menor que os adolescentes masculinos.

O autoconceito por gênero encontrado neste estudo, apresentando os homens como mais passivos, a partir dos adjetivos pouco ousados, pouco hedonistas, tímidos e inseguros, pode estar refletindo o estado de transição pelo qual passam os papéis de gênero, no qual a masculinidade perde sua agressividade "natural" e racionalidade dominante para relacionar-se mais com suas emoções, o que pode estar acarretando como consequência confusão e desorientação. Esta afirmação se confirma ao se verificar que entre os dez adjetivos com médias mais elevadas elencados pelos adolescentes masculinos emergem identificações como sonhadores, simpáticos, amorosos, cuidadosos, compreensivos e românticos, antes inerentes ao feminino.

Para os adolescentes masculinos a idade é fator preponderante na Percepção Negativa de Si e à tolerância, ou seja, quanto menor a idade, maior a Percepção Negativa de Si, e, contrariamente, quanto maior a idade, maior o autoconceito enquanto tolerante, evidenciando que o autoconceito se modifica com o decorrer dos anos, embora haja necessidade de estudos longitudinais que comprovem esta mudança. Para as adolescentes femininas ficou evidenciado que a Percepção Positiva de Si é maior entre os 16 e 18 anos. Estes resultados são coerentes com os encontrados por Marsh (1989) ao destacar que os primeiros anos da adolescência se caracterizam por mais negativismo que os anos mais tardios e que este tende a declinar da pré-adolescência até a metade dessa fase de desenvolvimento, quando então começa a aumentar.

Este dado também corrobora uma pesquisa realizada por Celen, Cok, Bosma e Djurre (2006) cujos resultados demonstraram que a autonomia, tomada de decisão e os conflitos tendem a diminuir com a idade, confirmando um autoconceito e Percepção Positiva de Si. Estes autores verificaram ainda a diferenciação de gênero, havendo pequena diferença: meninas têm maior nível de autonomia decisional e meninos experimentam mais conflitos.

A julgar pela relação entre os adjetivos e a faixa etária, emergindo inicialmente a identificação enquanto desagradável, desobediente, imoral, inacessível, injusto, mesquinho e vulgar, evoluindo com a idade para moral, responsável, objetivo, ao mesmo tempo em que emergem enquanto emotivos e sonhadores, observa-se que este fato pode estar relacionado com o desenvolvimento maturacional e a imposição de maior responsabilidade advinda com a idade.

A ênfase na preocupação profissional, em constituir família e o descrédito quanto ao futuro se mostram maiores com o passar dos anos. A psicologia do desenvolvimento preconiza que nos primeiros anos das vivências grupais, quer na vizinhança, quer na escola, as crianças estabelecem comparações, assentam similaridades, avaliam. É através da estratificação etária na escola, da estratificação socioeconômica no contexto da vizinhança, que pessoas similares se relacionam e, por meio 
de suas experiências, organizam o autoconceito, os objetivos e o quadro de referência pelo qual estabelecem a compreensão do mundo social (Gunther \& Gunther, 1998).

Escola e família constituem dois contextos de desenvolvimento fundamentais para a trajetória de vida das pessoas. Um estudo desenvolvido por Dessen e Polonia (2007) destaca as contribuições destes contextos para a promoção do desenvolvimento humano, enfatizando suas implicações nos processos evolutivos. Questões sobre configurações, vínculos familiares e a importância da rede social de apoio para o desenvolvimento da família são discutidas. Focalizam-se as funções da escola, considerando sua influência nas pessoas em desenvolvimento. Apontam-se algumas considerações sobre a necessidade de compreender as inter-relações entre escola e família, visando facilitar a aprendizagem e desenvolvimento humano. A integração entre esses dois contextos pode estar diretamente relacionada à construção de um autoconceito positivo de si e do mundo.

As perspectivas de futuro quanto às oportunidades para crescimento educacional e profissional, segundo Gunther e Gunther (1998), são fortemente marcadas por suas vivências educacionais e pelo contexto cultural: os jovens com condições de frequentar uma escola particular revelam melhores chances de vida, melhores expectativas quanto ao futuro. No Brasil, cada tipo de instituição escolar atende alunos de bases socioeconômicas diferentes, com a escola constituindo-se um produto social desigualmente distribuído, onde o tipo de escola e as desigualdades na condição de acesso já indicam a diferenciação do nível socioeconômico das famílias dos estudantes da rede de ensino público, onde as classes menos favorecidas têm uma única escolha - a das escolas públicas municipais ou estaduais (Camargo \& Bertoldo, 2006).

Um estudo realizado por Traverso-Yépez e Pinheiro (2005) na periferia da cidade de Natal-RN, Brasil, analisa as marcantes influências das relações de gênero, agravadas pela precariedade do contexto sócioeconômico, na socialização dos adolescentes, bem como as instituições escolares que frequentam. O estudo permite uma reflexão a respeito do permanente processo de construção da subjetividade adolescente, a partir das experiências de vida compartilhadas nas diferentes interações sociais, oferecendo sugestões para o trabalho de intervenção nas áreas da saúde e da educação.

No tocante, verifica-se a necessidade de um maior esforço para atingir as metas e perspectivas de vida que poden estar influenciando no autoconceito dos estudantes das escolas públicas deste estudo ao se definirem como mais organizados que os da escola privada. Enquanto os estudantes das escolas públicas definem-se como mais caprichosos, compreensivos, cuidadosos, frágeis, organizados, responsáveis, românticos, sentimentais e sonhadores, os estudantes de escolas privadas se definem mais negativamente, com adjetivos tais como agressivos, desatenciosos, desleixados, desobedientes, desorganizados, dominadores, grosseiros, intolerantes, intransigentes, irresponsáveis, irreverentes, irritados, maliciosos, violentos, mas também íntegros, morais, respeitosos, objetivos e ousados.

\section{Considerações finais}

De forma geral, foi observado que os adolescentes apresentam um autoconceito positivo, associados a uma auto-estima elevada, que pode constituir-se como um importante mecanismo protetor contra adversidades. $\mathrm{O}$ autoconceito positivo pode promover no indivíduo o desenvolvimento da resiliência (capacidade de superar adversidades), de forma que o indivíduo fique protegido contra experiências estressantes (Sapienza \& Pedromônico, 2005).

Apresentando um resultado diferente ao viés histórico, observa-se uma transformação no perfil do estudante da escola pública, que apresenta uma descrição mais positiva em relação ao da escola privada. Associada ao conceito de resiliência acima destacado, tal autopercepção pode constituir-se como um importante passo para uma reestruturação nos papéis sociais.

Os resultados desse estudo também nos apontam uma potencial mudança nos estereótipos sociais, sobretudo nos adolescentes masculinos, que segundo seus próprios relatos, passam a se definir a partir de características voltadas a passividade. Tais achados denotam um novo perfil que confronta uma herança histórica machista, também refletidos nos dados femininos, que contestam os estereótipos associados ao ex-sexo frágil, construindo, agora, uma postura com características relacionadas à passividade, equiparáveis as masculinas.

Por fim, destaca-se a reformulação do autoconceito com o transcurso da idade, sendo mais tolerantes aqueles mais velhos. O acompanhamento dessa transformação fornece subsídios especialmente para o contexto escolar que, informado sobre as características dos seus alunos, podem traçar medidas mais efetivas no alcance de determinados objetivos pedagógicos. Em suma, estar ciente destes achados, seja este relacionado a sexo, idade ou tipo de instituição frequentada, nos permite elaborar estratégias mais coerentes, que se adaptem melhor ao perfil dos adolescentes, seja no âmbito familiar, escolar ou social.

Algumas limitações metodológicas do presente trabalho devem ser levadas em consideração na discussão dos resultados obtidos. Inicialmente, é histórica a reticência dos estabelecimentos particulares de ensino em permitir a realização de pesquisas com seus alunos. Tal realidade acaba por implicar uma visão parcial da situação dos jovens estudantes, na qual a classe média e a alta não aparecem representadas em igualdade numérica, limitando a comparabilidade.

Além disso, os dados colhidos foram obtidos por meio do autorrelato, através de questionários objetivos. Essa limitação foi contornada utilizando-se os seguintes procedimentos: questionários anônimos, preenchimento voluntário, aplicação da pesquisa sem a presença de funcionários da escola e garantia verbal e escrita (na apresentação do questionário) quanto ao caráter confidencial das informações fornecidas. De todo modo, cabe considerar que a tendência mais provável de viés das informações obtidas seria no sentido de um sub-relato dos comportamentos pesquisados, uma vez que eles são, na ampla maioria dos casos, de natureza íntima. 


\section{Referências}

Assis, S. G., Avanci, J. Q., Silva, C. M. F. P., Malaquias, J. V., Santos, N. C., \& Oliveira, R. V. C. (2003). A representação social do ser adolescente: Um passo decisivo na promoção da saúde. Ciência \& Saúde Coletiva, 8, 669-679.

Bernardo, R. P. S., \& Matos, M. G. (2003). Desporto aventura e auto-estima nos adolescentes, em meio escolar. Revista Portuguesa de Ciências do Desporto, 3, 33-46.

Burns, R. B. (1979). The self concept. London: Longman.

Camargo, B. V., \& Bertoldo, R. B. (2006). Comparação da vulnerabilidade de estudantes da escola pública e particular em relação ao HIV. Estudos de Psicologia, 23, 369-379.

Celen, N., Cok, F., Bosma, H. A., \& Djurre, H. Z. (2006). A percepção de adolescentes e de pais sobre decisão e autonomia. Paidéia (Ribeirão Preto), 16, 349-363.

Cia, F., \& Barham, E. J. (2005). A relação entre o turno de trabalho do pai e o autoconceito do filho. Psico, 36, 29-35.

Coopersmith, S. (1967). The antecedents of self-esteem. San Francisco: Freeman.

Costa, P. C. G. (2002). Escala de Autoconceito no trabalho: Construção e validação. Psicologia: Teoria e Pesquisa, 18, 75-81.

D’Affonseca, S. M. (2005). Prevenindo fracasso escolar: Comparando o autoconceito e desempenho acadêmico de filhos de mães que trabalham fora e donas de casa. Dissertação de Mestrado não publicada, Universidade Federal de São Carlos, São Carlos, SP.

Da Cunha, C. A., Sisto, F. F., \& Machado, F. (2006). Dificuldade de aprendizagem na escrita e o autoconceito num grupo de crianças. Avaliação Psicológica, 5, 153-157.

Dessen, M. A., \& Polonia, A. C. (2007). A família e a escola como contextos de desenvolvimento humano. Paidéia (Ribeirão Preto), 17, 21-32.

Faria, L. (2005). Desenvolvimento do autoconceito físico nas crianças e nos adolescentes. Análise Psicológica, 23, 361371

Giavoni, A., \& Tamayo, A. (2000). Inventário dos Esquemas de Gênero do Autoconceito (IEGA). Psicologia: Teoria e Pesquisa, 16, 175-184.

Giavoni, A., \& Tamayo, A. (2003). Inventário Masculino dos Esquemas de Gênero do Autoconceito (IMEGA). Psicologia: Teoria e Pesquisa, 19, 249-259.

Gobitta, M., \& Guzzo, R. S. L. (2002). Estudo Inicial do Inventário de auto-estima (SEI) - Forma A. Psicologia: Reflexão e Crítica, 15, 143-150.

Gunther, I. A., \& Gunther, H. (1998). Brasílias pobres, Brasílias ricas: Perspectivas de futuro entre adolescentes. Psicologia: Reflexão e Crítica, 11, 191-207.

Ito, P.C.P., Gobitta, M., \& Guzzo, R. S. L.(2007). Temperamento, neuroticismo e auto-estima: Estudo preliminar. Estudos de Psicologia, 24, 143-153.
Lassance, M. C. P. (2005). Adultos com dificuldades de ajustamento ao trabalho: Ampliando o enquadre da orientação vocacional de abordagem evolutiva. Revista Brasileira de Orientação Vocacional, 6(1), 41-51.

Marsh, H. W. (1989). Age and sex effects in multiple dimensions of self-concept preadolescence to early adulthood. Journal of Educational Psychology, 81, 417-430.

Melo, G. F., Giavoni, A., \& Tróccoli, B. T. (2004). Estereótipos de gênero aplicados a mulheres atletas. Psicologia: Teoria e Pesquisa, 20, 251-256.

Myers, D. G. (2000). Psicologia Social. Rio de Janeiro: LTC.

Peixoto, F. (2004). Qualidade das relações familiares, autoestima, autoconceito e rendimento acadêmico. Análise Psicológica, 22, 235-244.

Saldanha, A. A. W. (2003). Vulnerabilidade e construções de enfrentamento da soropositividade ao HIV por mulheres infectadas em relacionamento estável. Tese de doutorado não publicada, Faculdade de Filosofia, Ciências e Letras de Ribeirão Preto, Universidade de São Paulo, Ribeirão Preto, SP.

Sapienza, G., \& Pedromônico, M. R. M. (2005). Risco, proteção e resiliência no desenvolvimento da criança e do adolescente. Psicologia em Estudo, 10, 209-216.

Sisto, F. F., \& Martinelli, S. C. (2004). Estudo preliminar para a construção da escala de autoconceito infanto-juvenil (EACIJ). Interação em Psicologia, 8, 181-190.

Souza, C. M. M. (2002). A afetividade na formação da autoestima do aluno. Monografia de conclusão não publicada, Universidade da Amazônia, Belém, PA.

Tabachinick, B. G., \& Fidel, L. S. (1996). Using multivariate statistics. New York: Harper Collins College Publishers.

Tamayo, A., Campos, A. P. M., Matos, D. R., Mendes, G. R., Santos, J. B., \& Carvalho, N. T. (2001). A influência da atividade física regular sobre o autoconceito. Estudos de Psicologia, 6, 157-165.

Traverso-Yépez, M. A., \& Pinheiro, V. S. (2005). Socialização de gênero e adolescência. Revista Estudos Feministas, 13, 147-162.

Ana Alayde Werba Saldanha é Professora Doutora da Universidade Federal da Paraíba.

Isabel Cristina Vasconcelos de Oliveira é graduanda em Psicologia da Universidade Federal da Paraíba.

Regina Ligia Wanderlei de Azevedo é doutoranda em Psicologia Social pelo Programa de Pós-graduação da Universidade Federal da Paraíba.

Recebido: $15 / 09 / 2009$

$1^{a}$ revisão: $04 / 01 / 2010$

$2^{a}$ revisão: $30 / 08 / 2010$

Aceite final: 16/12/2010 